\title{
Os Anos 1954-1963 no Politécnico de Milão
}

\section{Lembranças e Reflexões Sobre um Período que Revolucionou a Química Macromolecular}

\author{
Lido Porri (Politecnico de Milano - Piazza Leonardo da Vinci, 32 - 20133 Milano) \\ (tradução: Roberto Filippini Fantoni - AlM; cooperação: Silvio Manrich - ABPol)
}

Este artigo é o quarto transferido da AIM Magazine, a revista da Associação Italiana de Ciência e Tecnologia das Macromoléculas (AIM) com a qual a ABPol assinou um acordo de intercâmbio em 2006. Não se trata de um artigo científico, mas de um trecho importante de história da química macromolecular contada por um dos participantes diretos. Apesar das contendas que se desenvolveram durante aquele período histórico para decidir a paternidade do polipropileno estereoregular ficou claro que o mundo científico dos polímeros estava pronto para alcançar aquela meta. Muitos foram os pesquisadores que estavam trabalhando nesse domínio e a descoberta devia estar próxima. O grupo do Instituto de Química Industrial do Politécnico de Milão, liderado pelo prof. Giulio Natta, era aquele que estava mais perto de alcançar a tão almejada meta e os jovens que trabalhavam nesse projeto acumularam tanto e tão profundo conhecimento que tornaram-se, nos anos sucessivos, cientistas de grande valor nos vários setores conexos com os polímeros estereoregulares (cristalografia dos polímeros, estruturística estereoregular, mecanismos de reação, etc.).

Os prêmios Nobel ganhos conjuntamente por Natta e Ziegler em 1963 demonstraram que as intuições do primeiro sobre a possibilidade de sintetizar uma macromolécula estereoregular eram corretas e que os catalisadores desenvolvidos pelo segundo podiam ser idôneos para essa necessidade. Lido Porri, o autor do artigo, era um dos jovens do grupo de pesquisa e, portanto, a narração dessa história é feita por uma pessoa que a viveu diretamente, participando das aflições, das esperanças, das decepções e, finalmente, do sucesso final.

O prof. Porri não precisaria de uma apresentação sendo um cientista de fama internacional e mesmo bem conhecido no Brasil, pois colaborou com muitos cientistas brasileiros, mas sumarizaremos alguns pontos fundamentais da sua carreira mais para frente.

Escolhemos este artigo entre aqueles propostos da AIM, pois pensamos que, depois de 50 anos desses acontecimentos, os jovens pesquisadores devam saber o quão duro foi o trabalho para alcançar um resultado que, realmente, revolucionou a química macromolecular: esperamos que tudo isso seja excitante e estimulante o necessário para que eles possam enfrentar os desafios de hoje com muita vontade e determinação.

A polimerização estereoespecífica é uma das descobertas químicas mais significativas dos últimos decênios e traz uma marca toda italiana. Iniciou em junho de 1954 quando no Politécnico de Milão o prof. Giulio Natta e o seu grupo sintetizaram os polímeros isotáticos do propileno, do buteno-1 e do estireno, utilizando os catalisadores metalorgânicos descobertos pouco antes por Karl Ziegler na Alemanha.

Em Milão entenderam logo a importância inovadora dessa síntese e o trabalho foi dirigido sobre monômeros diferentes dos 1-alquenos: em breve tempo obtiveram-se homopolímeros e copolímeros estereoregulares utilizando várias classes de monômeros. Abria-se, assim, um novo capítulo da ciência das macromoléculas, de enorme importância científica e tecnológica, sobre o qual até hoje se trabalha intensamente no mundo inteiro.

Desde 1954 vários outros laboratórios, sejam universitários ou das grandes indústrias, iniciaram pesquisas com os catalisadores Ziegler, mas durante muitos anos, de 1954 até o início dos anos '60, o grupo de Natta manteve uma indiscutida liderança nesse campo. Ziegler e Natta receberam o prêmio Nobel de química em 1963, o primeiro pela descoberta dos catalisadores de polimerização baseados nos metais de transição, o segundo por ter aberto com esses catalisadores o capítulo da polimerização estereoespecífica.
Depois de cinquenta anos a importância do trabalho desenvolvido no Politécnico de Milão, parece mais evidente do que aparentava naquele tempo e nós nos perguntamos com um pouco de curiosidade quais foram os fatores de tal sucesso. São, sobretudo, os jovens que querem informações sobre aquele período, sobre Natta, a organização do grupo, quais recursos dispunham. Alguns dos pesquisadores já faleceram (Chini, Pino, Giachetti, Farina, Giannini, Corradini), outros estão aposentados ou, todavia, se ocupam de outros assuntos. Quem está escrevendo é um dos pouquíssimos que está ainda ativo na polimerização estereoespecífica. Alguns colegas me pediram que escrevesse algo sobre aquele período, algo que possa ser útil aos jovens, seja como informação, seja como estímulo.

\section{Breve Perfil de Giulio Natta}

Nascido em 1903, ele estudou no Politécnico de Milão, onde se graduou com o prof. Bruni no Instituto de Química Geral, que naquele tempo era considerado, na Itália, um dois mais avançados no campo estrutural. A sua carreira universitária foi rapidíssima: em 1933 foi nomeado professor de Química Geral na Universidade de Pavia, em 1935 foi nomeado na Universidade de Roma, professor de Química Física, em 1937 foi nomeado no Politécnico de Turim para a Cátedra de Química Industrial, para ele mais adequada, e enfim em 1938 foi chamado ao Politécnico de 
Milão para substituir o prof. M.G. Levi, afastado do ensino por causa das Leis Raciais.

Natta encontrou um Instituto bastante bem organizado para aqueles tempos. Depois da guerra iniciou uma colaboração com a Sociedade Montecatini, naquele tempo a maior indústria química italiana. Em 1952 instituiu, de acordo com a Montecatini, uma Escola de Aperfeiçoamento em Química Alifática, que era frequentada por químicos (preferivelmente) e engenheiros químicos recém empregados da Montecatini (15-20 participantes cada ano). A Escola consistia em poucas aulas teóricas e muito trabalho experimental. Ao fim do Curso os estudantes eram transferidos aos laboratórios e às plantas da Montecatini, mas Natta podia reter os melhores por um período indeterminado. A existência dessa Escola teve uma influência dificilmente avaliável sobre os desenvolvimentos que ocorreram em seguida, como iremos mostrar em breve. Relativamente aos interesses científicos, Natta no início dedicou-se prevalentemente aos estudos estruturísticos, continuando a tradição existente no Instituto no qual se tinha graduado. Depois se dedicou aos estudos de importantes temas da indústria química, como a extração do butadieno da fração C4, a síntese do metanol, a reação de hidroformilação, os catalisadores em geral como instrumento da síntese industrial.

Gostaria agora de mencionar um episódio que demonstra como Natta estivesse muito atento aos aspectos práticos da pesquisa. Um dos seus assistentes, nos anos depois da guerra, era Piero Pino, que procedia da Universidade de Florência, onde tinha colaborado com o prof. Giovanni Speroni. Pino era o assistente sob cuja guia me graduei em Florença. Depois de graduado fui empregado pelo Instituto Donegani de Novara (N.d.R. - Um primoroso Instituto de pesquisa que pertencia à Montecatini, atualmente ainda existente) e saindo de Novara eu ia frequentemente - sobretudo aos sábados - visitar amigavelmente Pino, que eu encontrava sempre trabalhando em seu pequeno laboratório no Instituto de Química Industrial do Politécnico de Milão. Pino desenvolvia pesquisas junto com o prof. Natta, mas também desenvolvia temas próprios. Numa tarde de sábado encontrei Pino um tanto prostrado e fomos juntos tomar um cafezinho num barzinho perto do Politécnico. Ele me explicou o motivo de seu mal estar. Pino tinha trabalhado por meses num tema herdado da

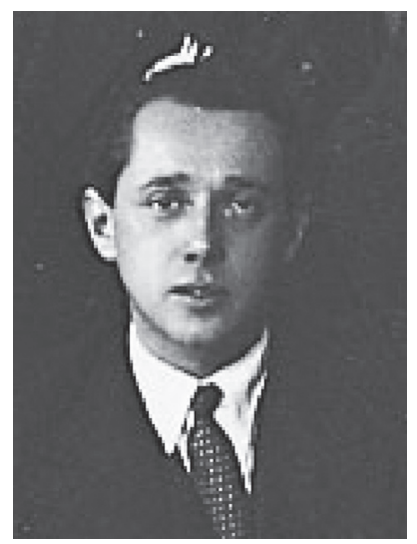

Figura 1. O jovem engenheiro Giulio Natta em 1932.

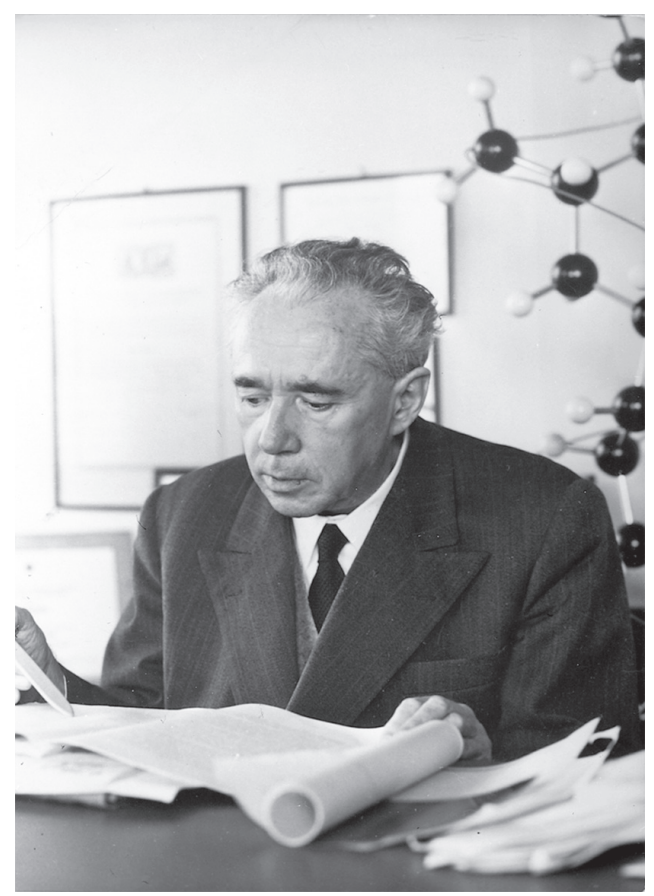

Figura 2. Giulio Natta na vigília do Prêmio Nobel em 1963.

Universidade de Florença, relativo à cinética da abertura do anel isossazólico em função dos substituintes ligados ao anel. Tinha obtido muitos dados e antes de publicá-los quis apresentá-los ao prof. Natta. Como de costume Natta escutou atenciosamente a apresentação do Pino, mas quando ele acabou saiu com este comentário: "Pino, o senhor acha que esses trabalhos têm alguma importância?" Pino se abalou, mas depois de alguns anos me disse que tinha aprendido muito com aquele episódio.

\section{A Polimerização Estereoespecífica}

O primeiro ato desta história iniciou-se em 1952 quando Natta participou da Achema de Frankfurt e ouviu uma conferência de Karl Ziegler, diretor do Max Plank Institut für Kohlenforschung di Mühlheim (N-d.R.- Instituto Max Plank para a pesquisa sobre o carbono), sobre um processo de oligomerização do etileno, catalisado com trietil alumínio. Ziegler e colaboradores tinham descoberto que o etileno, a cerca de $100{ }^{\circ} \mathrm{C}$ e 100 atmosferas, inserta-se entre as ligações $\mathrm{Al}-\mathrm{C}$ do $\mathrm{Al}\left(\mathrm{C}_{2} \mathrm{H}_{5}\right)_{3}$ e que depois de cerca de 100 inserções há, via "hydrogen abstraction", destaque de um oligômero do etileno que contém um grupo vinila na extremidade e formação de uma ligação Al-H. Este último, através de uma reação com etileno forma novamente a ligação Al-Et que recomeça o ciclo catalítico. Ziegler chamou essa reação "aufbaureaktion". Naquele tempo o etileno era polimerizado em plantas industriais com o método radicálico da ICI. Os oligômeros de Ziegler não pareciam ter um interesse industrial, mas, contudo, havia algo de interessante no processo. Pela primeira vez o etileno era oligomerizado para inserção do monômero sobre uma ligação metal-carbono, originando produtos lineares. Em linha de princípio não se podia excluir 
a possibilidade de obter produtos com peso molecular maior agindo sobre as condições experimentais.

Natta, naquele tempo consultor da Montecatini, sugeriu à sociedade italiana que adquirisse as patentes Ziegler relativas à "aufbaureaktion". Mais duas sociedades (Farbwerke Hoechst, na Alemanha; Petrochemical Ldt, na Inglaterra) adquiriram as patentes, pois acharam como Natta, que a reação pudesse ter interessantes desenvolvimentos. Uma cláusula do contrato estabelecia que Zigler teria que informar os proprietários da licença sobre os eventuais desenvolvimentos que ocorressem em Mühlheim durante as pesquisas sobre a "aufbaureaktion".

Como resultados desse contrato, três estudantes da Escola de Aperfeiçoamento (Paolo Chini, Roberto Magri, Giovanni Crespi) foram enviados a Mühlheim nos laboratórios do Ziegler para tomar conhecimento das técnicas experimentais necessárias para trabalhar com os alquil alumínio, substâncias altamente pirofóricas que pretendem um ambiente anidro e falto de oxigênio.

Em Milão alguns estudantes da Escola de Aperfeiçoamento iniciaram o trabalho sobre as reações de Ziegler. Particularmente Pino iniciou o exame, junto com o jovem estudante Mario Farina (N.d.R.- Bem conhecido estruturista macromolecular, um dos fundadores do AIM e fundador do Convênio-Escola de Gargnano que hoje chama-se ConvênioEscola "Mario Farina” em lembrança dele), a cinética da "aufbaureaktion". Os resultados desse estudo foram depois publicados em 1955 [Natta G, Pino P, Farina M. La Ricerca Sci 1955;25(Supp.):120].

Naturalmente o trabalho sobre a "aufbaureaktion" continuou mesmo em Mühlheim, com o intento de aprofundar o conhecimento da reação e, sobretudo, individuar os fatores que pudessem influenciar o peso molecular dos oligômeros. Durante essa experimentação um teste não deu os usuais oligômeros, mas só 1-buteno. Depois de alguns dias de febris pesquisas o grupo de Ziegler apercebeu-se que o resultado anômalo derivava do fato que a autoclave usada pelo teste estava suja de níquel, utilizado numa precedente reação. Portanto indagaram sistematicamente o efeito "aufbaureaktion" de vários compostos de metais de transição e aperceberam-se que o trietil alumínio, em combinação com alguns metais de transição, fornece catalisadores capazes de polimerizar o etileno até obter altos polímeros lineares em condições extremamente brandas, ou seja, mesmo a temperatura ambiente e por simples borbulho do monômero. $\mathrm{O}$ sistema mais eficaz foi aquele derivante da reação entre $\mathrm{AlEt}_{3}$ e $\mathrm{TiCl}_{4}$.

As patentes relativas à polimerização do etileno com os novos catalisadores descobertos por Ziegler foram apresentadas à Montecatini (e, portanto, a Natta) em dezembro de 1953. No Politécnico de Milão iniciou-se o trabalho com esses catalisadores no início de 1954. É difícil afirmar se Natta tinha inicialmente a intenção de utilizálos para polimerizar o polipropileno. Natta era uma pessoa muito concreta, sabia que Zigler ainda não tinha chegado a polimerizar o propileno e sabia também que na reação entre

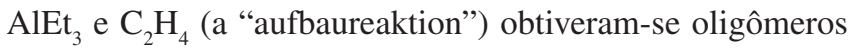

com grau de polimerização de cerca 100, enquanto do $\mathrm{AlEt}_{3}$ e propileno obtiveram-se somente dímeros. É possível que o primeiro pensamento de Natta não fosse de homopolimerizar o propileno, mas de copolimerizar etileno com propileno para obter elastômeros.

Foi, verossimilmente, durante esses experimentos sobre a copolimerização etileno/propileno que foi examinada também a homopolimerização do propileno. Depois de vários testes, Paolo Chini conseguiu individuar as condições para obter polipropileno de alto peso molecular. Natta escreveu em sua agenda de algibeira em 11 de Março de 1954: "Fatto il polipropilene" (N.d.R. - "Feito o polipropileno") (Figura 3).

$\mathrm{O}$ produto de polimerização pareceu heterogêneo, constituído de uma parte gomosa misturada com uma substância branca.

Seguindo uma sugestão de Pino o produto foi fracionado mediante extração à ebulição com solventes sucessivos: a acetona extraía produtos de consistência oleosa, oligômeros do propileno; o éter etílico extraía um produto gomoso, amorfo aos raios $\mathrm{X}$, constituído de polipropileno atático de alto peso molecular. O resíduo da extração etérea era um pó branco, cristalino aos raios $\mathrm{X}$. O método de fracionamento sugerido por Pino já era conhecido na literatura e fora utilizado pelos químicos alemães para a separação dos produtos da FisherTropsch (Pichler H. Brennst. Chem 1838; 19:226), mas ninguém sabia que fosse tão útil para o fracionamento do polipropileno. De fato este método permitia isolar frações com diferentes graus de estereoregularidade, um problema novo para os químicos macromoleculares daquele período. Não tem dúvida que este método de fracionamento acelerou notavelmente a caracterização do produto de polimerização do propileno.

Da fração cristalina preparou-se uma fibra (Natta o anotou sobre a sua agenda (Figura 4)) e do período de identidade, $6.25 \AA$, deduziu-se que a cristalinidade procedia da presença, nas macromoléculas, de longos tratos nos quais os átomos de carbono terciários tinham a mesma configuração.

Foi depositada uma patente (inventor Giulio Natta) em 8 de Junho de 1954, na qual se revingaram, entre outros, polímeros cristalinos do polipropileno, que tinham "uma estrutura regular, provavelmente espiraliforme, correspondente a um período de identidade de $6.4 \AA$ ”. Uma segunda patente

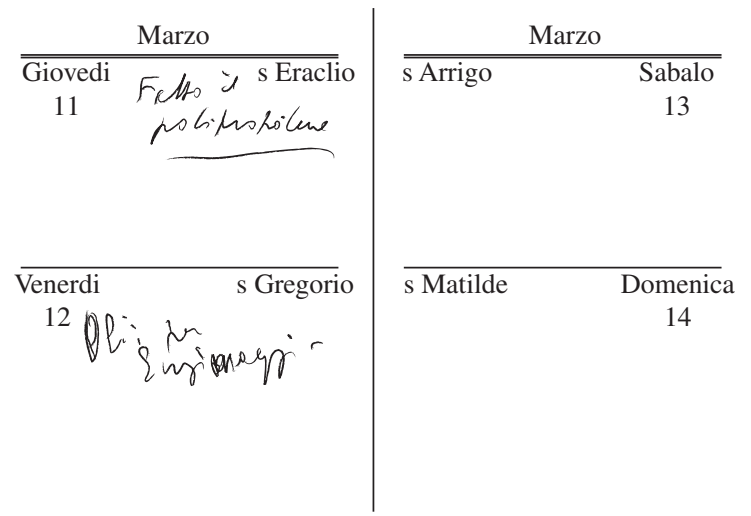

Figura 3. Da agenda de Giulio Natta Março 1954: "fatto il polipropilene" (N.d.T. "feito o polipropileno"). 


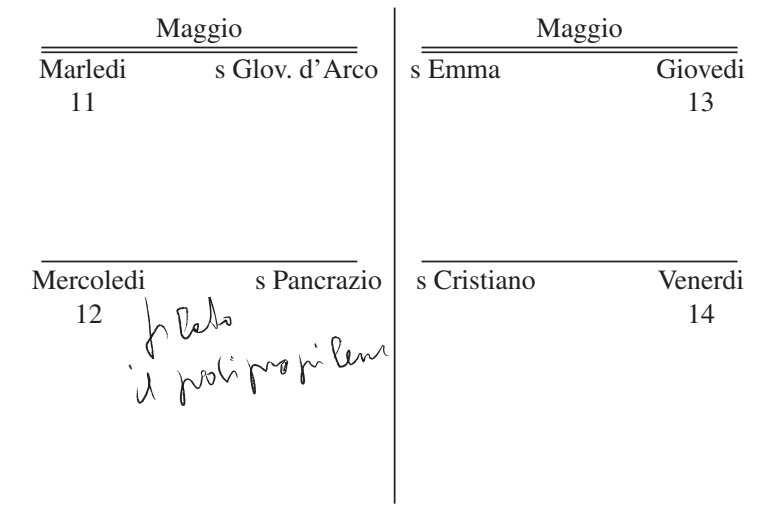

Figura 4. Da agenda de Giulio Natta maio 1954: "filato il polipropilene" (Nd.T. - "fiado o polipropileno".

(inventores Giulio Natta, Piero Pino, Giorgio Mazzanti) foi depositada em 27 de Julho sobre a polimerização, além do propileno, também do buteno-1 e o do estireno; também para esses monômeros foram obtidos polímeros cristalinos, para os quais foi determinada a estrutura (Figura 5).

Em 3 de Agosto de 1954, cerca de 8 semanas depois do depósito da primeira patente de Natta, também Ziegler depositou uma patente sobre a polimerização do propileno e do buteno-1 usando $\mathrm{AlEt}_{3}-\mathrm{TiCl}_{4}$ e sistemas análogos (inventores Karl Ziegler, Heinz Breil, Heinz Martin, Erhard Holzkamp). Na patente alemã se fala que se obteve um polipropileno sólido (feste polypropylene), foi anexado um espetro IR do polímero bruto, mas não se fala de análises aos raios $\mathrm{X}$ nem de fracionamento do produto.

Uma simples comparação entre as duas primeiras patentes, de Milão e de Mühlheim, indica que em Milão estavam conscientes daquilo que tinham obtido, enquanto em Mühlheim limitaram-se a observar que foi obtido um polímero sólido.

Voltando ao trabalho feito em Milão, surpreende o fato que o nome de Paolo Chini, que tinha efetuado a primeira síntese do polipropileno, não esteja presente nas duas patentes em Junho e Julho '54. Falando sucessivamente sobre esse assunto Pino atribuiu a si toda a responsabilidade dessa omissão, que o tinha magoado muito e que era atribuível talvez ao clima tenso do momento.

Se nós devemos atribuir a Chini o mérito de ter individuado por primeiro as condições experimentais para polimerizar o propileno (principalmente a relação molar $\mathrm{AlEt}_{3} / \mathrm{TiCl}_{4}$ e o jeito para preparar o catalisador, adição do $\mathrm{AlEt}_{3}$ ao $\mathrm{TiCl}_{4}$ ou vice-versa), temos que atribuir a Pino o mérito de ter indicado um método de fracionamento que simplificou enormemente a caracterização do produto de polimerização, e ao Corradini o mérito de ter determinado a estrutura do polipropileno cristalino.

Natta logo entendeu a importância científica e tecnológica dos polímeros cristalinos obtidos. Ele cunhou o têrmo isotático para indicar esses polímeros, têrmo que usou pela primeira vez numa comunicação pela Accademia dei Lincei em Novembro de 1954, publicada alguns meses depois (Natta G. - Atti Accademia Nazionale dei Lincei, Mem 1955;4:61). Deu-se um nome para algo de importante que nasceu e Natta tinha entendido, antes dos outros, que a síntese dos polímeros

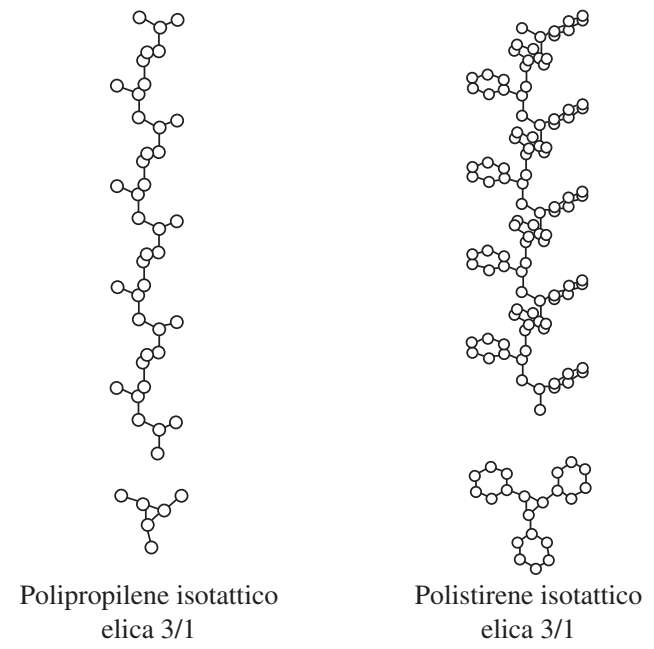

Figura 5. Conformação das macromoléculas de polipropileno e de poliestireno isotáticos no estado cristalino.

cristalinos das alfa-olefinas estava abrindo um novo capítulo e de grande importância na química macromolecular. Antes de 1954 a síntese dos polímeros estereoregulares era um monopólio da natureza: agora esse monopólio estava parcialmente quebrado.

Em Outubro de '54 o grupo de Milão aportou uma importante modificação ao catalisador Ziegler: no lugar do $\mathrm{TiCl}_{4}$ usou-se, em combinação com $\mathrm{AlEt}_{3}$, o $\mathrm{TiCl}_{3}$, do qual, naquele tempo se conhecia somente a modificação cristalina violeta. Se o polipropileno obtido com $\mathrm{AlEt}_{3}-\mathrm{TiCl}_{4}$ continha só cerca de $40 \%$ de produto cristalino, aquilo obtido com $\mathrm{AlEt}_{3}-\mathrm{TiCl}_{3}$ continha até o $80 \%$ da parte cristalina. Um progresso notável que abriu o caminho para a produção em grande escala do polipropileno em Outubro ' 57.

Falou-se e escreveu-se que este significativo melhoramento do sistema catalítico foi o resultado de uma lúcida intuição de Natta e do seu Grupo. Baseando-me em minhas lembranças as coisas foram muito mais simples e não existiu nenhuma fulgurante intuição. Uma manhã nós nos encontramos reunidos, perto de um banco de laboratório, Natta, Pino, Mazzanti, Giachetti, eu e talvez mais alguém. Lembro muito bem que alguém disse que talvez teria valido a pena testar o $\mathrm{TiCl}_{3}$ no lugar do $\mathrm{TiCl}_{4}$. Nossos conhecimentos sobre a natureza do catalisador eram, naquela época, muito escassos e era difícil dizer a priori se o $\mathrm{TiCl}_{3}$ poderia funcionar melhor ou pior do que o $\mathrm{TiCl}_{4}$. Todavia o $\mathrm{TiCl}_{3}$ foi testado, funcionou muito bem e foi solicitada uma patente.

Nos primeiros dias de Janeiro foi enviada uma comunicação ao Editor do J.Am.Chem.Soc., que fez conhecer à Comunidade Científica os primeiros resultados de Milão. A reação foi notável. O Prof. Paul J. Flory, naquele tempo um dos personagens mais eminentes no campo da química macromolecular e futuro prêmio Nobel de química (ganhou o prêmio em 1974) enviou uma carta ao Prof. Natta, na qual, entre outras coisas, escreveu: "The results disclosed in your manuscript are of extraordinary interest; perhaps one should call them revolutionary in significance. The possibilities opened up by such asymmetric polymerizations are of utmost importance, I am sure". 
Em Milão o clima tornou-se febril. Natta, além dos polímeros estereoregulares, pensava também nos copolímeros, sejam aqueles etileno/propileno para obter elastômeros saturados, como nos copolímeros insaturados vulcanizáveis com métodos clássicos. Quando cheguei ao Politécnico, se não estou errado em 19-20 de Agosto '54, Natta encarregou-me de examinar a copolimerização propileno/butadieno. Ele tinha já em mente a borracha-butilo, que é um copolímero do isobuteno com pequenas quantidades (3-4\%) de isopreno e pensava que um copolímero análogo do propileno com pequenas quantidades de butadieno pudesse ter interessantes propriedades. Ele achava difícil obter polímeros estereoregulares utilizando diolefinas conjugadas, por causa das várias maneiras com as quais esses monômeros podem polimerizar-se. Disse-me que em julho efetuara-se uma homopolimerização do butadieno com $\mathrm{AlCl}_{3}-\mathrm{TiCl}_{4}$, que fornecera um polímero completamente insolúvel e de difícil caracterização. Talvez se tenha obtido um polímero catiônico através a presença do $\mathrm{TiCl}_{4}$.

Iniciei o trabalho sobre a copolimerização propileno/ butadieno: obtivemos copolímeros, mas com rendimentos não muito interessantes. Todavia foi solicitada uma patente na qual se revingavam copolímeros propileno/butadieno e também copolímeros do propileno com diolefinas não conjugadas.

Em fins de '54 iniciei o trabalho sobre a homopolimerização do butadieno e de outras diolefinas naquele tempo disponíveis. Logo foi observada uma importante diferença entre a polimerização das alfaolefinas e das diolefinas. Enquanto na polimerização das alfa-olefinas eram altamente estereoespecíficos somente os catalisadores heterogêneos baseados nos cloretos de Ti, na polimerização das diolefinas resultaram ativos estereoespecíficos também catalisadores baseados nos V, $\mathrm{Cr}$, Mo, metais do VIII grupo e a estereoespecificidade não resultava ligada à heterogeneidade do catalisador. Chegaram rapidamente resultados interessantes. Em poucos meses de trabalho obtivemos do butadieno todos os quatro polímeros estereoregulares previsíveis para este monômero: 1,4-trans (Dezembro '54); 1,2 sindiotático (Abril '55); 1.2 isotático (Outubro '55); 1,4-cis (Abril '56), as datas são aquelas que se encontraram nos cadernos de laboratório). Polímeros estereoregulares foram também obtidos do isopreno e do 1,3-pentadieno. Lembro a surpresa e o gáudio de Natta quando lhe disse que fora obtido um polibutadieno cristalino com estrutura 1,2 no qual as unidades monoméricas tinham alternativamente configuração oposta. Tratava-se de um tipo de estereoregularidade que, mesmo em medida bastante modesta, foi já observada no poliacrilonitrila e no poli(cloreto de vinila) obtidos por via radicais livres, mas o novo polibutadieno 1,2 tinha um alto grau de estereoregularidade. Natta cunhou o termo sindiotático para indicar este tipo de polímero (o termo apareceu pela primeira vez no artigo Natta G. Makromol Chem 1955;16:213).

Então, pensou-se que as alfa-olefinas pudessem fornecer polímeros isotáticos e que as diolefinas, por motivos não claros, pudessem dar somente polímeros sindiotáticos. Mas em Outubro ' 55 , do butadieno foi obtido um polímero de estrutura
1,2 isotática. Pela primeira vez apercebeu-se que um mesmo monômero pode fornecer polímeros isotáticos ou sindiotáticos, dependendo do catalisador utilizado. Esses conceitos parecem agora banais, mas naquele tempo o resultado surpreendeu.

A síntese dos dois butadienos de estrutura 1,2, um isotático e o outro sindiotático, estimulou a procura do polipropileno sindiotático que aconteceu em 1959. Tenho uma lembrança relativa a esse ponto. Um dia Natta me chamou no escritório dele e quando cheguei estava acabando uma discussão com dois colaboradores de Corradini. Objeto da discussão eram alguns espectros de raios $\mathrm{X}$ do polipropileno isotático, obtido com particulares sistemas catalíticos. Esses espectros apresentavam algumas difrações não presentes nos espectros dos polímeros obtidos com os catalisadores normalmente utilizados, baseados no trialquil alumínio e $\mathrm{TiCl}_{3}$. Os estruturistas pensavam numa modificação cristalina do polipropileno isotático, mas as evidências favoráveis eram fracas. Eu lembro que Natta, depois da conclusão da discussão, aventou a hipótese de que as novas difrações fossem imputáveis ao polipropileno sindiotático. Ele disse que se o butadieno tinha dado dois polímeros estereoregulares com estrutura 1,2, um isotático e o outro sindiotático, não se via porque o polipropileno não pudesse dar um polímero sindiotático. Encarregou o prof. Pegoraro de separar por cromatografia sobre coluna (fase sólida polipropileno isotático de alta estereoregularidade) o componente responsável pelas anômalas difrações, que efetivamente resultou ser polipropileno sindiotático. Essa era uma característica de Natta: sabia encontrar a exata interpretação em situações aparentemente não claras.

Já disse que Natta era inicialmente bastante cético sobre a possibilidade de obter resultados interessantes da polimerização de diolefinas conjugadas, pois esses monômeros podem gerar vários tipos de unidades monoméricas. Mesmo assim, quando os resultados chegaram, ele ficou positivamente surpreso. Em Dezembro '57, no Politécnico, ele apresentou a prolusão da abertura do ano acadêmico '57-'58, durante a qual ilustrou os principais resultados obtidos no seu Instituto sobre a polimerização estereoespecífica. Na prolusão ele disse, entre outras coisas: "Os mais sensacionais resultados nas catálises estereoespecíficas, porém, foram obtidos no campo das borrachas elásticas cristalizáveis. Faz mais de 50 anos que os químicos esforçavam-se para obter produtos sintéticos que tinham as propriedades da borracha natural..... Todas as tentativas para reproduzir a borracha elástica porém, fracassaram. Nonosso Politécnico obtiveram-se todos os quatro polímeros de estrutura regular previsíveis para o butadieno, assim como a primeira borracha elástica que apresenta as excepcionais propriedades da borracha natural".

É interessante reler, à distância de muitos anos, a prolusão de Natta, que encontra-se no site (www.polipress.polimi.it). Fica bem claro quais foram as suas preferências num vasto campo como aquele da polimerização estereoespecífica, que abrange desde a organometálica até a catálise, a estereoquímica, a caracterização química, física e tecnológica dos produtos. Natta estava deslumbrado, sobretudo com o interesse industrial dos novos polímeros. 
Até agora falei bastante da parte relativa às diolefinas, pois este era o campo no qual eu trabalhava, mas existiam vários grupos de trabalho. Cada grupo era constituído por um pequeno núcleo permanente e por colaboradores, todos recém empregados da Montecatini, que permaneciam um ou mais anos e depois eram empregados nos laboratórios da Sociedade. $\mathrm{O}$ grupo maior era aquele que trabalhava sobre a homo e a copolimerização das alfa-olefinas, mas grupos menores trabalhavam sobre monômeros funcionalizados, sobre as olefinas cíclicas, e também existiam grupos dedicados à caracterização física e tecnológica dos produtos. Os nomes de todos os componentes do grupo de Milão (uns deles são reconhecíveis nas Figuras 6-10), são encontrados nas Nobel Lecture de Natta, publicadas em várias revistas (Chimica e industria 1964;46:597; Angew Chemie 1964;76:553; Science $1965 ; 147: 261)$.

Para o grupo inteiro de Natta os anos que vão de 1954 até ao inicio dos anos ' 60 foram anos de intenso trabalho e de grandes satisfações. Iniciando em '59 começaram a chegar ao Politécnico de Milão bolsistas das EUA, da Inglaterra, do Canadá, e da Academia das Ciências da União Soviética. Em 1961 o Journal of Polymer Science, naquela época uma das mais cotadas revistas científicas no campo dos polímeros, dedicou um número (Vol.51, issue 156) a Natta, chamado pela revista o pai dos polímeros estereoregulares. É interessante ler as primeiras frases da introdução escrita pelo Editor da revista para dar-se conta da consideração que Natta e a sua escola desfrutavam no mundo.

"Seldom has a scientific contribution aroused such profound fundamental interest and has been followed by such a rapid technical development as the series of publications by Professor Giulio Natta and his coworkers on the stereospecific polymerization of olefins, which started to appear in the Italians journals several years ago and have continued ever since. Many prominent scientists in many large research laboratories have become interested in the new technique and have focused their interest and efforts in their promotion. Yet Professor Natta has succeeded in maintaining undisputed leadership in this field of polymer chemistry and continues to surprise his colleagues by new and unexpected results".

É difícil narrar em poucas linhas o conjunto dos resultados obtidos em Milão. Foram sintetizados dezenas de homopolímeros estereoregulares como olefinas, diolefinas, olefinas cíclicas com anel pequeno (ciclobuteno e norborneno) e demais copolímeros alternados estereoregulares (etileno/ buteno 2.cis, etileno/ciclopenteno, etileno/butadieno), Foram também sintetizados copolímeros etileno/propileno com caráter elastomérico. Polímeros estereoregulares foram obtidos mesmo de monômeros não hidrocarbônicos como alguns viniloeteres, metoxiestireno, N-vinilocarbazol, benzofurano, utilizando vários tipos de catalisadores.

Devemos lembrar que algumas das estruturas sintetizadas não encontram confrontação na Natureza, por exemplo, os polímeros sindiotáticos. Em 1958 foi obtido um polímero cristalino com estrutura trans utilizando o sistema $\mathrm{AlEt}_{3}-$ $\mathrm{Ti}(\mathrm{OBu})_{4}$. É justo lembrar essa síntese, por que treze anos depois o químico japonês Shirakawa usou o mesmo sistema

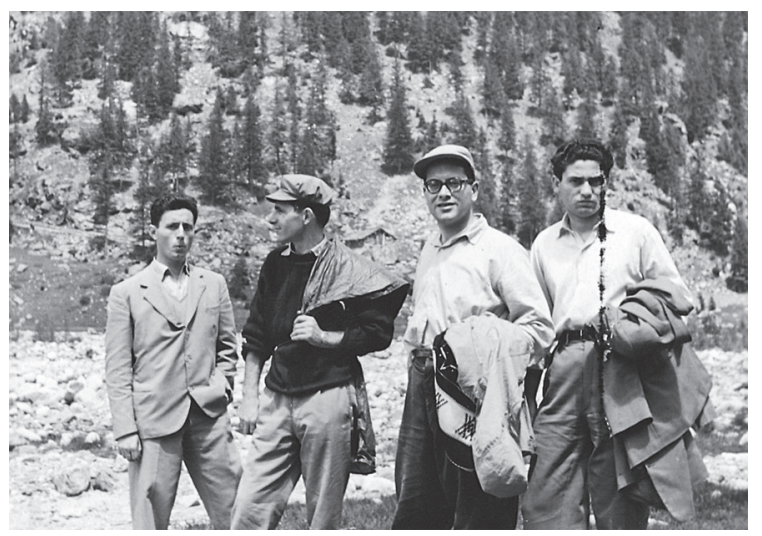

Figura 6. Alguns colaboradores de Natta, a passeio nas montanhas durante um fim de semana (1955?). Da esquerda: Umberto Giannini, Ivano Walter Bassi, Paolo Corradini, Romano Mazzocchi.

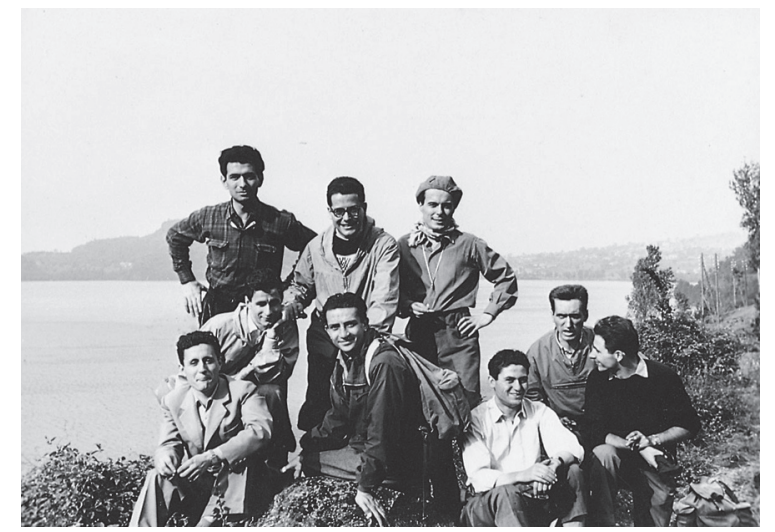

Figura 7. Foto de alguns colaboradores do prof. Natta (1955?). De pé da esquerda: Attilio Palvarini, Paolo Corradini, Mario Ragazzini. Sentados: Umberto Giannin, Giorgio Gaudiano, Giorgio Mazzanti, Romano Mazzocchi, Paolo Chini, Ivano Walter Basso.

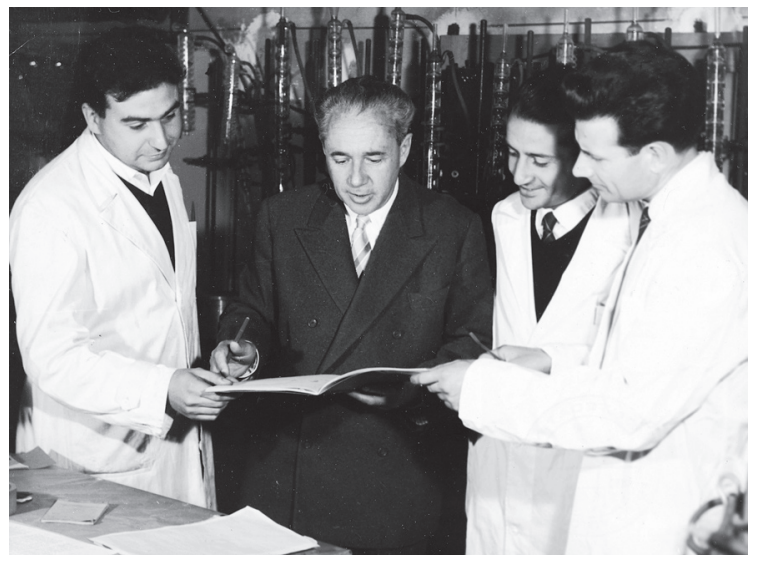

Figura 8. Natta junto com alguns colaboradores em 1958 (da esquerda: Mario Farina, Giorgio Mazzanti, Lido Porri).

para obter um filme de poliacetileno que em seguida, em colaboração com McDiarmid e Heeger, dopou com iodo, obtendo o primeiro polímero orgânico condutor. Shirakawa, McDiarmid e Heeger obtiveram o premio Nobel de química pelos trabalhos de pioneiros sobre os polímeros condutores. $\mathrm{O}$ primeiro desses polímeros foi mesmo o poliacetileno, obtido com o sistema utilizado em ' 58 em Milão.

O trabalho do grupo Natta não se limitou à síntese de polímeros estereoregulares. Foram descobertos novos 


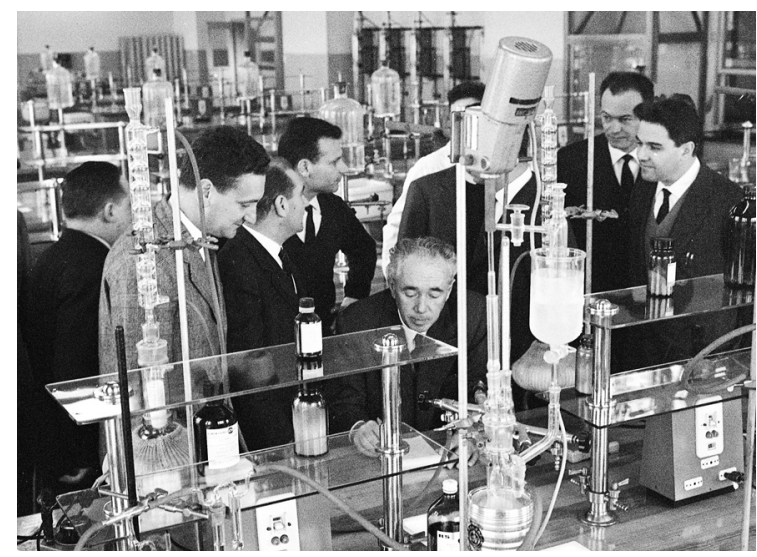

Figura 9. Natta junto com alguns dos seus colaboradores num laboratório do Politécnico (Outubro 1963). Da esquerda: Gino Dall'Asta (di spalle), Piero Pino, Ítalo Pasquon, Lido Porri, Giulio Natta, Raffaele Ercoli, Enrico Mantica.

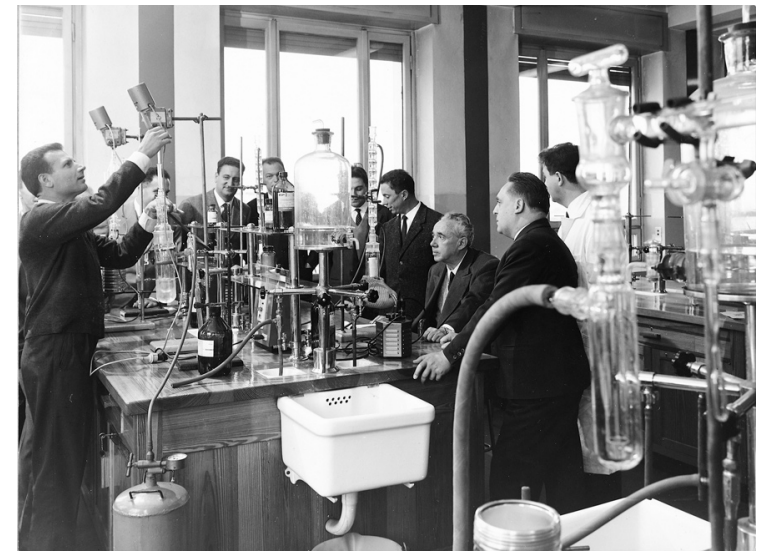

Figura 10. Natta num laboratório do Politécnico junto com alguns colaboradores (Outubro 1963). Da esquerda: Lido Porri, Piero Pino, Raffaele Ercoli, Enrico Mantica, Ferdinando Danusso, Gino Dall'Asta, Mario Farina.

sistemas catalíticos altamente estereoespecíficos, além disso, foi realizada pela primeira vez uma polimerização assimétrica na qual, operando com catalisadores opticamente ativos, foram obtidos polímeros opticamente ativos utilizando monômeros não quirales. Paralelamente ao estudo da polimerização foi feito o estudo da estrutura cristalina dos novos polímeros e das propriedades físicas deles, o que deu a possibilidade de evidenciar a estreita relação existente entre a disposição espacial dos átomos das macromoléculas e as propriedades físicas e tecnológicas dos polímeros. Além disso, foram aplicados sistematicamente à química macromolecular os conceitos da estereoquímica clássica: sobre esse assunto trabalhou principalmente Mario Farina, prematuramente falecido em 1994. Um quadro completo do conjunto dos resultados obtidos em Milão no período '54-'63 encontra-se na Nobel Lecture de Natta, "Das polimerizações estereoespecíficas à síntese assimétrica auto-catalítica de macromoléculas", já mencionada.

Depois da síntese dos primeiros polímeros estereoregulares o grupo de Milão examinou novamente alguns trabalhos e patentes comparecidos antes de ' 54 e notou que polímeros que tinham estrutura isotática já tinham sido obtidos, mas ninguém os tinham apercebido.
Nos anos 1947-1949, C.E. Schildknecht do Stevens Institute of Technology de Hobochem (New Jersey, USA), tinha obtido polímeros cristalinos de alguns alquil-viniléteres, operando a baixa temperatura com iniciadores catiônicos. Baseando-se no período de identidade $(6,2 \AA)$ Schildknecht levou em consideração várias possibilidades para a estrutura dos seus polímeros, mas enfim concluiu que a cristalinidade era verossimilmente devida àquele tipo de estereoregularidade que hoje chamamos de sindiotática. Os polímeros foram novamente examinados em Milão e resultaram ter, ao contrário, estrutura isotática.

Deve-se lembrar que um estruturista do ICI, C.W. Bunn, em 1942 tinha previsto (Proc. Roy. Soc. 1942; A 180:67) que num polímero vinílico que tinha aquele tipo de regularidade estérica que hoje chamamos de isotática, as macromoléculas teriam tido uma conformação espiralada com período de identidade cerca de 6,2 $\AA$, o mesmo valor encontrado por Schildknecht para os seus alquil-vinil-éteres. O trabalho de Bunn era pouco conhecido, talvez porque publicado no período de guerra, um período no qual a difusão dos trabalhos científicos não era fácil. Também em Milão o trabalho de Bunn não era conhecido. Se Schildknecht, em 1949, tivesse lido o trabalho de Bunn teria atribuído uma estrutura correta aos seus poli(alquil-vinil-éteres); ao contrário, se Bunn tivesse lido, em 1949, os trabalhos de Schildknecht teria percebido o erro cometido por este último. Se tudo isso tivesse acontecido, a história da polimerização estereoespecífica teria tomado outro caminho.

$\mathrm{Na}$ segunda metade dos anos '40, A.A. Morton, da Universidade de Akron (UEA), tinha individuado novos catalisadores para a polimerização do butadieno, os assim chamados catalisadores Alfin, constituídos de Na-allil, Naisopropilato e $\mathrm{NaCl}$. Com esses catalisadores Morton tinha polimerizado também o estireno, mas não tinha caracterizado o polímero, talvez porque o interesse dele estivesse concentrado no polibutadieno. O poliestireno Morton foi re-examinado em ' 55 e foi descoberto que tinha estrutura isotática, como aquele sintetizado um ano antes em Milão.

No início dos anos '50 a Standard Oil e a Phillips tinham patenteado a polimerização do etileno e do propileno com catalisadores a base de óxidos de molibdênio (Standard Oil) e óxidos de cromo (Phillips) suportados sobre sílica/alumina. O polipropileno obtido com esses catalisadores foi examinado em Milão. O produto Standard continha, além das unidades monoméricas propilênicas, também unidades derivantes do etileno, que se formou através da metátese do propileno e portanto não podia ser considerado do ponto de vista da patente como polipropileno. O produto Phillips era, ao contrário, polipropileno e em Milão demonstraram que continha quantidades muito pequenas de polipropileno isotático. $\mathrm{O}$ grupo de Natta foi certamente quem encontrou facilidade ao examinar o produto Phillips, pois possuía uma caracterização completa do polipropileno isotático, facilmente obtenível com os sistemas a base de $\mathrm{TiCl}_{4}$ ou $\mathrm{TiCl}_{3}$. Natta e colaboradores num trabalho referiram os resultados do exame do polipropileno Phillips (Natta G, Pino P, Mazzanti G, Chimica e Industria 1955; 37:927) e este trabalho foi depois usado pela Phillips contra a Montecatini numa "litigation" por patente, que continuou em 
Tabela 1. Polímeros cristalinos sintetizados no período 1947-1954. Somente depois dos trabalhos de Natta apercebeu-se que alguns polímeros sintetizados antes de '54 tinham estrutura "isotática".

\begin{tabular}{lcc}
\hline 1947 & C. E. Schildknecht & Polialchilvinileteri \\
1950 & A. A. Morton & Polistirene \\
1950 & Standard Oil Co. & Polipropilene \\
1951 & Phillips & Polipropilene \\
1954 & G. Natta & Polipropilene (8 junho) \\
1954 & K. Ziegler & Polipropilene (3 agosto) \\
\hline
\end{tabular}

seguida. Nos EUA a patente sobre o polipropileno isotático foi concedida à Phillips, pois essa sociedade tinha efetivamente obtido em 1951 um polipropileno isotático, como o trabalho de Natta já mencionado tinha efetivamente demonstrado. A Phillips não tinha se apercebido de tê-lo obtido. Mas segundo a lei americana a patente do produto foi concedida. Um exame detalhado dos problemas de patentes relativos à síntese do polipropileno isotático foi descrita num belo trabalho de P. Pino e G. Moretti (Polymer 1987;28:683).

\section{Prêmio Nobel}

Natta recebeu o Prêmio Nobel de química em 1963, junto com Karl Ziegler (Figura 11).

Muitos pensam que o prêmio foi conferido pela síntese do polipropileno isotático, que é sem dúvida o mais importante do ponto de vista industrial entre os polímeros estereoregulares sintetizados em Milão. Na realidade o prêmio foi conferido por ele ter aberto um capítulo novo no campo da química macromolecular, o capitulo da polimerização estereoespecífica, como aparece claro na motivação do prêmio: “......Nature synthesizes many stereoregular polymers, for example cellulose and rubber. This ability has so far been thought to be a monopoly of Nature operating with biocatalysts known as enzymes. But now Professor Natta has broken this monopoly.........Professor Natta, you have succeeded in preparing by a new methods macromolecules having a spatially regular structure. The scientific and technical consequences of your discovery are immense and cannot even now be fully estimated".

Passaram-se 44 anos do prêmio Nobel e ainda percebemos que o capítulo aberto em Milão é mais vital do que pensavase naquele tempo. Lembro-me que Natta várias vezes disse: "Penso que neste campo trabalhar-se-á ainda no próximo século". (Ele foi profético).

Mas quais são os motivos de tanto sucesso? Podemos dar várias respostas, mas na minha opinião, os motivos do sucesso são principalmente dois:

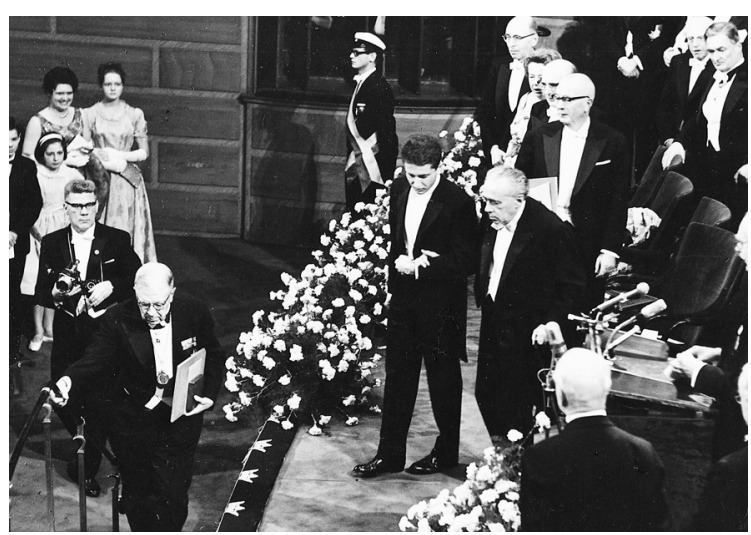

Figura 11. Giulio Natta, pelo braço do filho, está indo para receber o Prêmio Nobel por Gustav VI Adolf. Atrás do Prof. Natta se vê o prof. Karl Ziegler.

a) a organização que Natta tinha dado ao seu Instituto, onde trabalhavam sobre o mesmo tema químicos, estruturistas, espectroscopistas, tecnólogos, o que permitia um "aproche" interdisciplinar aos problemas. A maioria dos pesquisadores do grupo Natta era constituída de jovens empregados da Montecatini, sem os quais teria sido impossível manter por muito tempo a "undisputed leadership" mencionada no número citado do Journal of Polymer Science. É justo também lembrar que a Montecatini além dos homens, fornecia também os recursos, ou seja aparelhagens e produtos;

b) o intuito do Professor Natta, que tinha uma mente criativa direcionada tanto aos problemas científicos como aos industriais. Ele dava liberdade a seus pesquisadores, mas avaliava de modo correto cada resultado que chegava. Tinha entendido, antes dos outros, que os catalisadores descobertos por Ziegler estavam revolucionando a química macromolecular. Os nomes que cunhou para os polímeros estereoregulares, isotático e sindiotático, são uma demonstração que ele advertia que estava nascendo algo de novo. A este propósito, é interessante lembrar o que escreveu o Professor A.V. Tobolsky, da Princeton University, num artigo intitulado "Revolution in Polymer Chemistry" publicado em 1957 (American Scientist 1957;45:34): “..... Natta and coworkers, using Ziegler type catalysts, prepared isotactic polypropilene and polystyrene, among other. It was Natta who first recognized the chemical revolution that was taking place".

Concluindo, segundo a opinião de quem está escrevendo a presença de uma mente intuitiva, animada de insaciável curiosidade científica e de um grupo de trabalho constituído por jovens dotados de capacidade experimentais e de fantasia, foram a base do sucesso de Milão.

\section{Lido Porri é professor emérito da Faculdade de Engenharia do Politécnico de Milão.}

Graduado em química na Universidade de Florência, depois de um período de trabalho no Instituto de pesquisa "Guido Donegani" de Novara, em 1954 foi transferido para o grupo Montecatini que estava trabalhando no Politécnico de Milão, no Instituto dirigido por Giulio Natta: aí ficou até Janeiro do 1968. De primeiro de Fevereiro de 1968 até 30 de Outubro 1973 foi professor de química macromolecular e de química orgânica industrial na Universidade de Pisa. Em fins de 1973 retornou ao Politécnico de Milão como professor de química industrial. Trabalhou principalmente no campo da polimerização estereoespecífica das poliolefinas sintetizando inúmeros polímeros estereoregulares, individuando novos sistemas catalíticos e fornecendo uma interpretação, até hoje considerada válida, de vários aspectos do mecanismo da estereoespecificidade nas polimerizações de olefinas. 